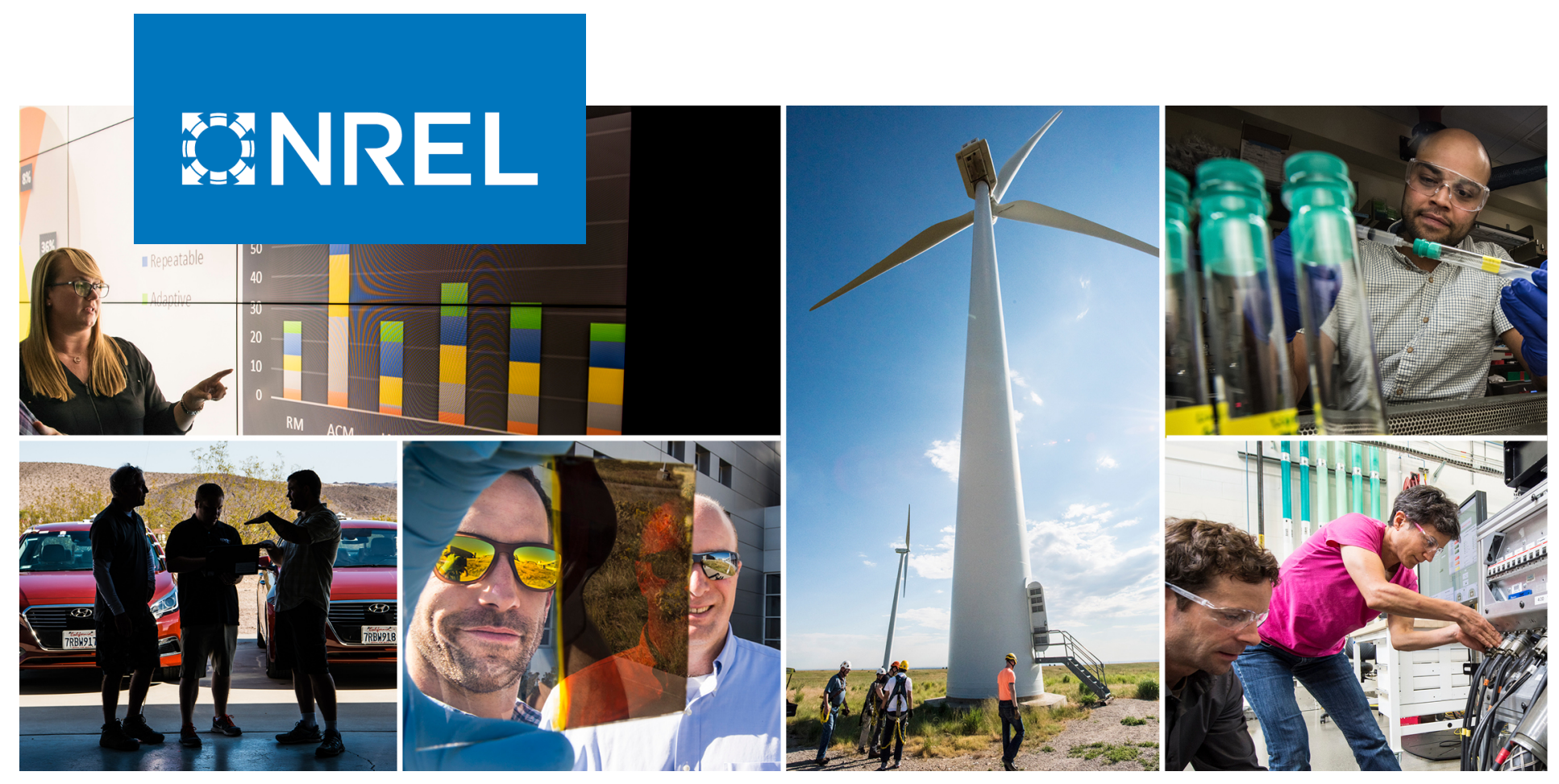

\title{
Microgrids, Infrastructure Resilience, and Advanced Controls Launchpad (MIRACL): Use Cases and Definitions
}

Jim Reilly, ${ }^{1}$ Jake Gentle, ${ }^{2}$ Alice Orrell, ${ }^{3}$ and Brian Naughton ${ }^{4}$

1 National Renewable Energy Laboratory

2 Idaho National Laboratory

3 Pacific Northwest National Laboratory

4 Sandia National Laboratories

NREL is a national laboratory of the U.S. Department of Energy Office of Energy Efficiency \& Renewable Energy

Operated by the Alliance for Sustainable Energy, LLC

This report is available at no cost from the National Renewable Energy Laboratory (NREL) at www.nrel.gov/publications.
Technical Report

NREL/TP-7A40-76918

February 2021 


\title{
EANREL
}

\section{Microgrids, Infrastructure Resilience, and Advanced Controls Launchpad (MIRACL): Use Cases and Definitions}

\author{
Jim Reilly, ${ }^{1}$ Jake Gentle, ${ }^{2}$ Alice Orrell, ${ }^{3}$ and \\ Brian Naughton ${ }^{4}$
}

\author{
1 National Renewable Energy Laboratory \\ 2 Idaho National Laboratory \\ 3 Pacific Northwest National Laboratory \\ 4 Sandia National Laboratories
}

\section{Suggested Citation}

Reilly, Jim, Jake Gentle, Alice Orrell, and Brian Naughton. 2021. Microgrids, Infrastructure Resilience, and Advanced Controls Launchpad (MIRACL): Use Cases and Definitions. Golden, CO: National Renewable Energy Laboratory. NREL/TP-7A40-76918.

https://www.nrel.gov/docs/fy21osti/76918.pdf.

NREL is a national laboratory of the U.S. Department of Energy Office of Energy Efficiency \& Renewable Energy Operated by the Alliance for Sustainable Energy, LLC

This report is available at no cost from the National Renewable Energy Laboratory (NREL) at www.nrel.gov/publications.

Contract No. DE-AC36-08GO28308
Technical Report

NREL/TP-7A40-76918

February 2021

National Renewable Energy Laboratory 15013 Denver West Parkway Golden, CO 80401

303-275-3000 • www.nrel.gov 


\section{NOTICE}

This work was authored in part by the National Renewable Energy Laboratory, operated by Alliance for Sustainable Energy, LLC, for the U.S. Department of Energy (DOE) under Contract No. DE-AC36-08GO28308. Funding provided by the U.S. Department of Energy Office of Energy Efficiency and Renewable Energy Wind Energy Technologies Office. The views expressed herein do not necessarily represent the views of the DOE or the U.S. Government. This report is available at no cost from the National Renewable Energy Laboratory (NREL) at www.nrel.gov/publications.

U.S. Department of Energy (DOE) reports produced after 1991 and a growing number of pre-1991 documents are available free via www.OSTI.gov.

Cover Photos by Dennis Schroeder: (clockwise, left to right) NREL 51934, NREL 45897, NREL 42160, NREL 45891, NREL 48097, NREL 46526.

NREL prints on paper that contains recycled content. 


\section{Acknowledgments}

This document was a collaborative effort among multiple U.S. Department of Energy national laboratories. In addition to the authors listed on the first page, substantial input and review was provided by the following authors and peer reviewers:

- Benjamin Anderson (NREL)

- Ian Baring-Gould (NREL)

- Bishnu Bhattarai (PNNL)

- Steven Bukowski (INL)

- Phylicia Cicillio (INL)

- Rachid Darbali (SNL)

- Jack Flicker (SNL)

- Juliet Homer (PNNL)

- Venkat Krishnan (NREL)

- Ram Poudel (NREL)

- Robert Preus (NREL)

- Craig G. Reiger (INL)

- Andrew Reiman (PNNL)

- Felipe Wilches-Bernal (SNL) 


\section{Introduction}

This resource document is designed to establish common use cases and definitions for U.S. Department of Energy national laboratories and partners participating in the Microgrids, Infrastructure Resilience, and Advanced Controls Launchpad (MIRACL) effort.

Use case definitions can be used to classify and connect research-and-development efforts and ultimately to organize project goals. Establishing use cases will also allow for the definition of operational benchmarks for various elements of the MIRACL project and broader distributed wind program as well as enable future alignment with other distributed energy resource research projects.

\section{Definitions}

\section{Use Case}

A use case is a concept used in system analysis to identify, clarify, and organize system requirements. In MIRACL and other distributed wind research, use cases will span the wide variety of distributed wind projects and form the basis of MIRACL discussions and targeted work packages. Distributed wind projects will be categorized into use cases with similar requirements, challenges, and benefits, such as:

- Technical (interconnection, certification, integration with other renewable energy systems)

- Financial (cost structure, valuation)

- Market (developer, owner)

- Resilience (energy security, cybersecurity, fuel diversity, financial security).

The high-level use cases defined for MIRACL, as shown in Figure 1, encompass wind turbines in:

1. Isolated grids

2. Microgrids

3. Behind-the-meter deployments

4. Front-of-the-meter deployments.

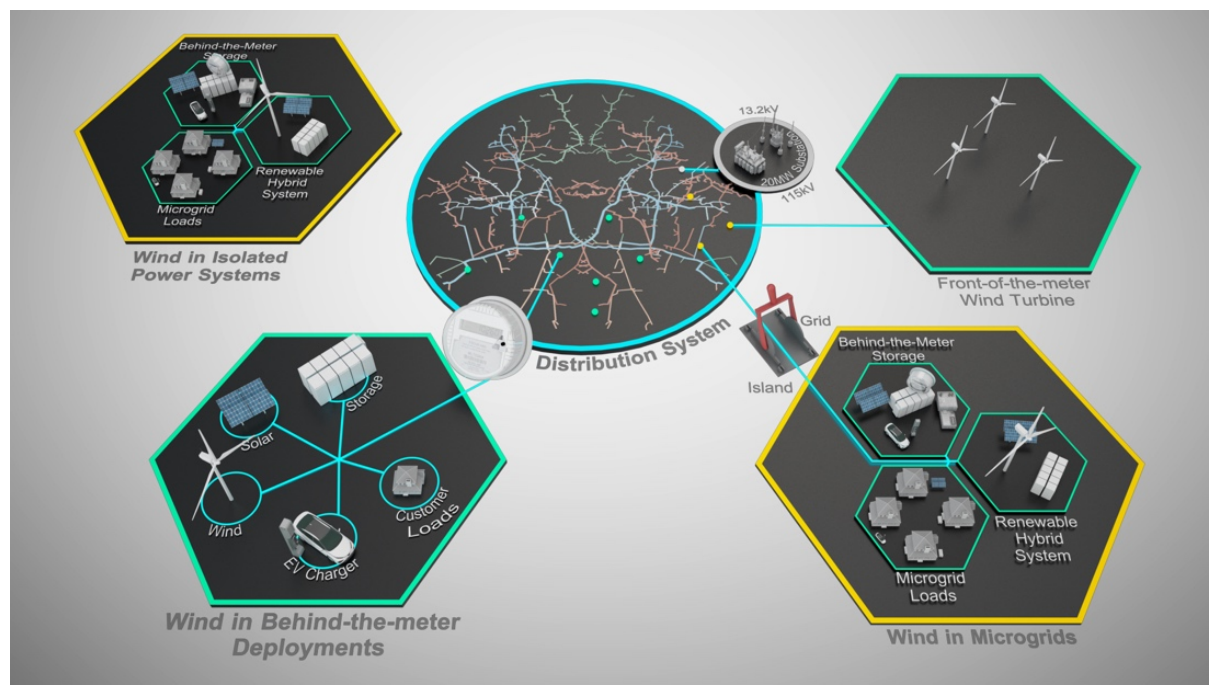

Figure 1. MIRACL use cases graphic 
Although this document focuses on wind, the use cases encompass systems with any single or combination of distributed energy resources and could apply to research beyond distributed wind.

\section{Reference System}

Reference systems used in MIRACL research will be operational distributed wind systems that can be tracked over time and that have a significant amount of data available (such as detailed economic and technical information) to inform analysis and laboratory or field demonstrations of hardware and software innovations within research work packages.

\section{Case Study}

MIRACL case studies are in-depth investigations of specific phenomena or capabilities in the context of a reference system that can be further studied through MIRACL research. There may be several specific case studies for each use case, demonstrating the varying system configurations, challenges, and benefits within each use case.

Case studies can be analyzed in an entirely simulated environment, in the lab with some combination of physical hardware and simulation, or in a deployed system or systems using real-world data and/or hardware. MIRACL could use case studies both to characterize and investigate phenomena observed in real or simulated systems and/or to apply innovations developed through the project to such systems to assess their value or to demonstrate their readiness for use by industry in commercially deployed systems.

\section{Benchmark}

Benchmarks will define theoretical or simulated systems to align research across the topic areas, work packages, and use cases. Benchmarks can be informed by reference systems but may also incorporate theoretical elements to evaluate and track technical progress. A benchmark will be a developed system model, such as standard Institute of Electrical and Electronics Engineers test cases, of which research can be performed in a simulated environment, such as GridLAB-D or MATLAB/Simulink, potentially with a hardware-in-loop component. The MIRACL team can define technical baselines and improvement targets based on these benchmark systems.

\section{Technical Parameter}

A technical parameter is a single element of a system that can be measured, varied, or incorporated into a reference or benchmark system to simulate a specific distributed wind deployment in a case study.

To enable research on specific technical challenges, several additional technical parameters associated with the reference or example system to be studied require definition. While the number and type of technical parameters needing definition will vary by use case and specific reference or example system, common technical parameters could include:

1. Wind turbine size (e.g., turbine rating, rotor diameter, and/or generator capacity)

2. Wind turbine type and features (levels of control capability for grid services)

3. Other distributed energy resources (energy storage, solar, fossil) in the mix and the capacity and/or energy contribution of each

4. Wind energy contribution (installed capacity, time contribution, and instantaneous contribution)

5. Resource availability and cost (wind profile, solar profile, fuel distribution costs) 
6. Load characteristics (power factor, total harmonic distortion, machine/resistive/electronic composition, load management, diurnal or seasonal variation)

7. Market structure (tariff structure, regulatory environment, other system values). 


\section{MIRACL Use Case 1: Isolated Grids}

\section{Description}

Isolated grids remain electrically independent of a bulk power grid. They may consist of several different generation technologies (wind, photovoltaics, diesel), storage (battery, thermal, mechanical), and system control. Systems with high contributions of wind often include an advanced level of supervisory control. Systems will typically operate at voltages below 100 kilovolts $(\mathrm{kV})$.

- Technical characteristics: Isolated grid, multiple distributed energy resources, potential storage, and active load control

- Financial characteristics: The need for remote power is highly dependent on the cost of imported fuel combined with its transport and storage. Reliability, resilience, and fuel security become larger noneconomic (but financially motivated) considerations.

- Market characteristics: Isolated, remote, and/or temporary communities, utilities, state or federal government facilities.

\section{Potential Reference System Types}

- Systems installed in Alaskan villages (Toksook Bay, Kodiak, Kotzebue, and St. Mary's)

- Systems at temporary military contingency bases (forward operating bases)

- Systems at isolated permanent military bases (San Clemente Island, Saint Nicholas Island)

- Systems in island communities. 


\section{MIRACL Use Case 2: Wind in Microgrids}

\section{Description}

A microgrid is a group of interconnected loads and distributed energy resources within defined electrical boundaries that can operate either connected or disconnected (islanded) from an external grid. A microgrid may consist of several different generation technologies, storage, and system control. Example systems range from small backup power systems using single turbines to relatively large systems for military bases and communities. Islanded mode is typically used for backup power during a disruption or to shed load from the grid as a grid service. Transition between grid-connected and islanded mode is a critical function.

- Technical characteristics: Normally grid-connected, able to island, multiple distributed energy resources

- Financial characteristics: Value of guaranteed energy supply

- Market characteristics: Communities needing energy security in the event of a grid outage.

\section{Potential Example and Reference Systems}

- Backup power systems for normally grid-connected loads (cell towers)

- Islandable systems serving grid-connected communities (Ocracoke Island)

- Islandable systems serving grid-connected military bases (Joint Base Cape Cod at Otis, Camp Smith)

- Islandable co-op-owned distribution systems. 


\section{MIRACL Use Case 3: Behind the Meter}

\section{Description}

Behind-the-meter systems are always connected to the grid behind the utility meter and are typically directly connected to load, including net metering (for the purposes of this document and MIRACL research, islandable systems that are behind the meter are considered under Use Case 2: Microgrids).

Behind-the-meter systems could comprise several different generation technologies and storage with a goal to better manage meter-level energy usage, including potentially auxiliary services even if those are primarily focused on addressing behind-the-meter energy quality. They may include some level of supervisory control to address/direct specific operational considerations. System configuration and size can vary greatly, from a single turbine to relatively complex power systems that could include hybrid distributed generation and storage technology that provide better control of energy draw from the utility.

- Technical characteristics: Behind the meter, remote/virtual net metering

- Financial characteristics: Offset retail rates, potential decrease of capacity or other power quality charges, potential green power credits, hedge against potential power cost variability

- Market characteristics: Those who want to be more self-sufficient, to be environmentally responsible, to displace high utility bills, or to hedge against energy costs that are likely to increase in the future.

\section{Potential Example and Reference Systems}

- Military

- Commercial/institutional (including academic and commercial campuses)

- Industrial

- Residential. 


\section{MIRACL Use Case 4: Front of the Meter}

\section{Description}

Front-of-the-meter systems are always connected to load-serving distribution grids. Systems could be made up of several different generation technologies and storage with a goal to provide energy at locations of need while supporting other auxiliary services. Front-of-the-meter systems may include some level of supervisory control to address/direct specific operational considerations and are generally dispatched by a relevant utility. Project size can vary greatly from one turbine to multiple turbines, but systems are generally no larger than 20 megawatts (MW).

- Technical characteristics: Grid-connected systems, distribution voltages, sometimes on weak grids, potential for advanced control

- Financial characteristics: Compete with wholesale rates, potential to provide auxiliary or grid support services, potential green power credits, hedge against potential power cost variability

- Market characteristics: Utilities wanting resource diversity, can be owned by the utility or an independent power provider, may require implementation under the Public Utility Regulatory Policies Act.

\section{Potential Example and Reference Systems}

- Utility-owned

- Energy cooperatives

- Municipal energy systems (Fire Island Wind Farm in Alaska's Railbelt region). 